\title{
CADÍES Y ALCAIDES DE LA FRONTERA ORIENTAL NAZARÍ (S. XV)
}

María ARCAS CAMPOY

Universidad de La Laguna

En el archivo Municipal de Lorca se conserva en dos volúmenes la primera parte del pleito sostenido entre esta ciudad y la de Vera por la delimitación de sus términos, desde el año 1511 al 1559. Las declaraciones - traducidas al castellano- de los testigos de las partes en litigio, antiguos súbditos del reino nazarí, de avanzada edad, constituyen una valiosa fuente de información acerca de muchas y variadas facetas de la vida y de la historia de un espacio territorial y temporal muy concretos: la frontera oriental granadina en la segunda mitad del siglo XV.

De este documento, que se puede calificar de excepcional por su naturaleza y contenido, proceden los datos y noticias utilizadas en este trabajo cuyo objeto es contribuir, dentro del marco de la práctica jurídica, al conocimiento de la actividad judicial en los años finales del último territorio del Islam andalusí, en concreto, de las competencias, actuaciones y jurisdicciones no sólo del cadí sino también del alcaide, otro importante representante de la justicia.

El primer fruto de mi investigación sobre la práctica del fiqh en el citado pleito ha sido el artículo «Noticias sobre el cadiazgo en los últimos años del reino nazarí: La frontera entre Murcia y Granada ${ }^{1}$. En él he abordado algunos aspectos del funcionamiento del cadiazgo en esta zona, tema que en el presente trabajo me propongo ampliar y completar con nuevos datos. Al citado artículo han seguido otros ${ }^{2}$ sobre diferentes cuestiones de la práctica jurídica en el mismo espacio territorial y documentados en la misma fuente.

\footnotetext{
* Este trabajo, presentado como comunicación en la II Joseph Schacht Conference on Theory and Practice in Islamic Law: «The role on qā dis in Islamic law: theory and practice» (Granada, diciembre 1997), forma parte del Proyecto de Investigación, Jueces en acción: La práctica jurídica en al-Andalus, del que es investigadora responsable M. ${ }^{a}$ Isabel Fierro Bello, Instituto de Filología del Consejo Superior del Investigaciones Científicas (PB 96-0867).

1 Revista del Centro de Estudios Históricos de Granada y su Reino, núm. 6, segunda época (1992), 203-210.

2 «La práctica jurídica en la frontera oriental nazarí (2. ${ }^{a}$ mitad del siglo XV)», Actas del Congreso "La frontera oriental nazarí como sujeto histórico (s. XIII-XVI)" (Lorca-Vera 1994), Almería 1997, 293-299; «Ortodoxia y pragmatismo del figh. Los homicianos de la frontera oriental nazari”, 18th Congress of the Union Européenne des Arabisants et Islamisants (Leuven 1996), ed. U. Vermeulen and J. M. F. Van Reeth, en Orientalia Lovaniensia Analecta 86 (1998) - Law Christianity and Modernism in Islamic Society-, 75-85.
} 


\section{CADÍES}

Son abundantes las referencias a los cadíes ( $q \bar{a} d \underline{l} \bar{l}, p l . q u d \bar{a} t)$ y al ejercicio del cadiazgo ( $q a d \bar{a}^{\prime}$ ) ofrecidas por los testigos de las partes en litigio ${ }^{3}$, si bien destacan en número los de Vera. Los aspectos que se deben señalar son los siguientes: a) la sede judicial de Vera y su cadí; b) la jurisdicción territorial; c) el nombramiento de los cadíes; d) las competencias de los cadíes; e) jueces delegados, secretarios y alfaquíes.

a) La sede judicial de Vera y su cadí

Más de cincuenta testigos de la parte de Vera dan fe de la existencia de un cadí -muy pocos utilizan los términos justicia y juez- en la ciudad de Vera, mientras que por la parte contraria sólo uno (Luis El Begeri, PL, fol. 8v, año 1511) alude a este hecho.

Son mencionados los siguiente cadíes de la sede judicial de la ciudad fronteriza:

- Habraen Yaçid o Habrahen Aben Yaçid, padre del testigo Gonzalo Yaçid (PV, fol. 161r, 203r-205r, 212r, año 1550), quien indica que su padre fue cadi de la çiudad de Vera y alfaqui y tiniendo estos cargos este testigo estuvo con el d(ic)ho su padre en la d(ic)ha çiudad de Vera tiempo de dos años poco mas o menos. Según la declaración, que se remonta a sesenta y cinco años, se puede situar al citado cadí ejerciendo su cargo en Vera entre los años 1485 y 1487.

- El Xehera, mencionado por Françisco de Tufa, de 75 años (PV, fol. 170r, año 1550) por referencias de personas ancianas. No es posible ubicar cronológicamente su cadiazgo.

- Hamete El Cadi, importante personaje de la ciudad de Vera y su entorno, como se verá más adelante, cuyo nombre alude al cargo. El testigo Françisco de Tufa (PV, fol. 169r-170r, año 1550) lo menciona junto al anterior como cadí de Vera e igualmente su declaración sobre este punto se basa en referencias. También es citado por los testigos Diego Elague (PV, fol. 209v, 121v,

${ }^{3}$ En las referencias a los testigos indico el volumen del pleito - Parte de Vera (= PV) y Parte de Lorca (=PL)—, el folio y el año. 
año 1550), y Françisco Fajardo 4 (PV, fol. 248, año 1559). Otro personaje, que podría ser su padre, aparece en la declaración de Diego Lopez (PV, fol. 1r, año 1511), como Alcadi el Biejo que era justiçia de la dicha çiudad de Vera.

- El Alçir, natural de Almería. Diego El Chilichi (PV, fol. 201v-202r, año 1550) refiere que, durante los siete años que residió en Vera, el citado El Alçir era el cadí de esta ciudad.

\section{b) La jurisdicción territorial}

Si bien queda claro que en Vera existía una sede judicial con su cadí, no ocurre lo mismo respecto a su jurisdicción territorial ${ }^{5}$. La causa de esto, apuntada al principio, radica en las encontradas posturas de las partes litigantes: los de Vera defienden que la jurisdicción de su cadí se extendía a varias aldeas y villas cercanas sin cadí, como es el caso de Huércal y Overa ${ }^{6}$ cuya anexión por ambas partes constituye el objeto del pleito, mientras que los de Lorca alegan que cada ciudad o villa tenía su propio cadí y que no dependían unos de otros.

No obstante la contradicción señalada, los testigos de ambas partes ofrecen noticias de interés. Por la parte de Vera, en todas las declaraciones aparece dicha ciudad como sede judicial con un cadí bajo cuya jurisdicción estaban varias poblaciones vecinas, carentes de cadí. La mayoría de los testigos, desde 1511 hasta 1559, indican que Huércal y Overa siempre dependieron en todos los aspectos, incluido el judicial, de la ciudad de Vera. Martin de Monteagudo (PV, fol. 137, año 1534) afirma que, cuando en las dos villas mencionadas ocurría algo, proveya e castigava el cadí de Vera. Como él, otros muchos mantienen esta postura.

En el año 1550 se pregunta (PV, fol. 200v) si saben que en tiempo de moros los cadis de la dicha çiudad de Vera conoçian y castigavan los delitos que se

\footnotetext{
4 Aparece como aljamiado, es decir, conocedor de la lengua de los no árabes ('aŷam) que aquí se refiere al castellano o romance, términos empleados indistintamente por algunos testigos.

5 Calero Secall, M. ${ }^{\text {a }}$ I., «Sedes judiciales malagueñas en época nazarí», Baetica, 7 (1984), 1, apunta que la delimitación del distrito judicial se hacía en función de que cualquier persona pudiera ir y volver a la sede del cadí dentro del día. Si esto no fuera posible, «el cadí disponía de un auxiliar o sustituto, el $n \bar{a}$ 'ib, que actuaba en su nombre ejerciendo justicia en puntos alejados de la sede y sólo en asuntos inmobiliarios y de herencias».

6 Sobre la villas de Huércal y Overa hay que destacar los documentados trabajos de Jiménez Alcázar, J. F., «Huércal y Overa: entre dos reinos (1488-1520)», Actas del II Congreso de Historia de Andalucía (Córdoba, 1991), en Historia Medieval (II), Córdoba, 1994, 393-399; y Huércal y Overa: De enclaves nazaries a villas cristianas (1244-1571), Huércal-Overa, 1996.
} 
cometían en los dichos lugares de Guercal y Overa como en lugares, tierra, termino e juridiçion de la dicha çiudad de Vera. Diego El Chilichi, anteriormente citado, afirma que ambas villas carecían de cadí por lo que dependían judicialmente de El Alçir, titular de la sede de Vera. El testigo Gonçalo Yaçid cuyo padre, Abrahem Yaçid, había sido cadí de la ciudad fronteriza, indica el nombre de otras poblaciones dentro de la jurisdicción de Vera. Dice que cuando tenian nezesidad del dicho su padre en los lugares de Oria, Cantoria y en todos los otros lugares del rrio de Almanzora para conozer de qualesquier pleytos çiviles que se ofreçian entre los vecinos de los dichos lugares para fazer cartas de docte o partiçiones de bienes lo ynbiavan a llamar. Un testigo de la parte de Lorca, Luis El Begeri (PL, fol. 8v, año 1511), incluye a Cuevas en la jurisdicción del cadí de Vera.

Asimismo, otro testigo llamado Françisco Navarro Elorayguaz (PV, fol. 219v, año 1550), que vivió un tiempo en Arboleas, menciona la sede judicial de Purchena a cuya jurisdicción pertenecían los lugares que estan del lugar de Arboleas en adelante a la villa de Serena.

Las declaraciones de los testigos dejan bien claro que para resolver los asuntos tocantes a la justicia en las poblaciones dependientes de Vera había dos opciones: o sus habitantes acudían ante el cadí de esta ciudad, o éste se desplazaba a los distintos lugares de su jurisdicción. Alonsso El Taverna (PV, fol. 206v-206v, año 1550) avala la primera opción alegando que hera uso y costunbre usada y guardada entre los moros que los v(ecin)os de los lugares del rreyno de Granada no podian yr a otro cadi ninguno mas de al cadi que estava mas zercano de los tales lugares. En términos muy parecidos se expresa otro testigo, llamado Fernando El Hadid (PV, fol. 207v-208r, año 1550), quien además refiere un dato importante sobre el procedimiento judicial. Dice, refiriéndose al cadí de Vera y a los habitantes de Huércal y Overa, que cuando el dicho cadi no les haçia justiçia que apelavan del e yban por apellaçion ante el cadi mayor que estava y rresidia en la dicha çiudad de Granada. Según su declaración, los habitantes del reino de Granada podían ejercer el derecho de apelación ante el cadí supremo, en contra de lo admitido como norma general acerca de la inexistencia de tribunales de apelación constituidos, si bien desde la época califal existieron precedentes de revisión de sentencias ante el cadí de Córdoba ${ }^{7}$

\footnotetext{
${ }^{7}$ Sobre la inexistencia de tribunales de apelación en al-Andalus, vid. Lévi-Provençal, E., Historia de España Musulmana (dirigida por Menéndez Pidal), V, 20 ed., Madrid 1956, 76; Arcas Campoy, M., «La correspondencia de los cadíes en el Muntajab al-aḥkām de Ibn Abī Zamanīn», Actas del XII Congreso de l'Union Européenne des Arabisants et Islamisants (Málaga, 1984), Madrid, 1986, 48.
} 
Los testigos de la parte de Lorca se pronuncian sobre esta cuestión de manera muy distinta. Tanto las preguntas formuladas como las respuestas de los mismos defienden la total soberanía de las villas de Huércal y Overa en todos los aspectos, entre ellos el judicial ${ }^{8}$, alegando que dependían directamente del rey de Granada. Ninguno de ellos menciona la existencia de un cadí en las villas objeto del pleito, pero la mayoría lo hace implícitamente al argumentar la presencia de cadíes nombrados por el monarca en diversos lugares del territorio granadino. Así consta en la declaración de Juan El Cantori (PL, fol. 164v, año 1550), quien menciona a un cadí de Benamaurel y en las efectuadas el año 1558 por Garçia El Forruchel (PL, fol. 234r), Gonçalo Hernandez Axir (PL, fol. 234v), Pedro de Málaga (PL, fol. 234v) y Miguel Fotox Aluani (PL, fol. 234v235r).

c) El nombramiento de los cadíes

Una vez más los intereses enfrentados de las partes del pleito son la causa de que las noticias sobre este punto no coincidan, pues aunque unos y otros afirman que los cadíes son nombrados por el monarca granadino, los de Vera se refieren a su cadí, como único titular de su sede y de las villas de su jurisdicción, mientras que los de Lorca se refieren a los cadíes de todas las poblaciones, sin relación alguna de dependencia.

En 1511, Luis El Begeri (PL, fol. 8v, año 1511) declara que el rey de Granada había puesto como juez de Vera a una persona de su casa. La declaración de Fernando El Hadid (PV, fol. 207v, año 1550) alude a la designación del cadí de Vera por el soberano, pero con mayor precisión, se pronuncia Gonzalo Yaçid (PV, fol. 203r/205v, año 1550), indicando que su padre, el cadí Abrahen Yaçid, tenia provission del rrey moro que en aquella sazon rreynava que se llamava Muley Abulhazen 9 .

Son más numerosos los que aluden al cadí supremo (qā ḍ̆ $\left.a l-\hat{y} a m \bar{a}^{‘} a\right)$ como la persona que nombraba los cadíes, si bien hay que tener en cuenta que sus actuaciones estaban supervisadas por el monarca ${ }^{10}$. El testigo Alonsso El

${ }^{8}$ Sólo Luis El Begeri (PL, fol. 8v, año 1511) afirma que Cuevas dependía del cadí de Vera, aunque no menciona que ocurriera lo mismo con Huércal y Overa.

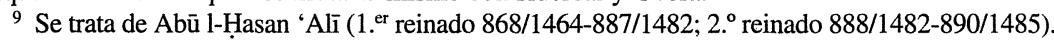

${ }^{10}$ Los cadíes supremos de Granada han sido estudiados por Calero Secall, M. ${ }^{a}$ I., «Cadíes supremos de la Granada Nașrí,, Actas del XII Congreso Union Européenne des Arabisants et Islamisants (Málaga 1984), Madrid, 1986, 135-149; vid. también Arcas Campoy, M., «Noticias sobre el cadiazgo», 208-209. 
Taverna (PV, fol. 206r-207v, año 1550) indica que el cadí de Vera estava puesto y nombrado por el cadi que estava y rresidia en la çiudad de Granada, que hera el cadi mayor.

Por la parte de Lorca, se formulan dos preguntas muy parecidas a los testigos en 1550 (PL, fol. 164r) y 1558 (PL, fol. 233v-234r) sobre el nombramiento de los cadíes ${ }^{11}$. Tanto las preguntas como las respuestas (Juan El Cantori, PL, fol. 164v, año 1550; Graçia El Forruchel, PL, fol. 234r, año 1558; Gonzalo Hernandez Axir, PL, fol. 234v, año 1558; Pedro de Málaga, PL, fol. 234v, año 1558; Miguel Fotox Aluani, PL, fol. 234v-235r, año 1558) indican que sólo el monarca y su cadí mayor, residente en Granada, tenían autoridad para ello y reiteran que era de todos conocido el hecho de que por todo el territorio nazarí circulaban cadíes para resolver determinados asuntos civiles. Uno de los testigos, Gonçalo Fernandez Axir, precisa en su declaración que el cadí mayor era como padre sancto, lo que supone una clara alusión al carácter religioso del cadiazgo, utilizando una transposición conceptual y linguística del contexto árabe e islámico al castellano y cristiano.

d) Las competencias de los cadíes ${ }^{12}$

Algunos testigos aluden a las competencias del cadí, indicando que arreglaban pleitos y diferencias, o que proveían y castigaban, mientras que otros definen y precisan la naturaleza de las actuaciones judiciales en una sola materia, civil o penal. Son escasos los que adjudican al cadí competencias en ambas materias. Todo ello, aparentemente contradictorio, parece tener coherencia si se analiza el contexto de las declaraciones.

Cuando los testigos de la parte de Vera se refieren al cadí titular de la ciudad y de las poblaciones de su distrito, concretamente Huércal y Overa, suelen reconocerle competencias en materia civil y penal. En este sentido se pronuncian varios testigos, confirmando el contenido de dos preguntas formuladas al respecto en el año 1559. El aljamiado Françisco Fajardo (PV, fol. 249r, 252r252v, año 1559), Jorge Mahariz (PV, fol. 250v, año 1559), Vartolome Sanchez

1 Véase parte del texto de dichas preguntas en Arcas Campoy, M., «Noticias sobre el cadiazgo», 205-207.

${ }^{12}$ Al-Nubāhī, al-Marqaba al-'ulyà fí man yastaḥiqq al-qadăa' wa-l-futyà, ed. de E. LéviProvençal, El Cairo 1948, 2-21, trata de todas las cuestiones referentes al cadí y al ejercicio de su cargo; en las pp. 2-6, alude a sus principales atribuciones. V. también, Tyan, E., Histoire de l'organisation judiciare en pays d'Islam, Leiden, 1960, deuxième edition, 342-403. Arié, R., L'Espagne musulmane au temps des Nasrides (1232-1492), Paris, 1990, 278-287. 
El Barami o El Barromi (PV, fol. 251r, 253r-253v, año 1559), entre otros, declaran que el cadí de Vera usava de la jurisdiçion çevil e criminal.

Sin embargo, la mayoría de los testigos de Vera se centran en las actuaciones del cadí en materia civil y aluden al alcaide como responsable de los casos criminales, creando así una serie de dudas e interrogantes que más adelante trataré de explicar.

Respecto a los asuntos civiles sobre los que el cadí de Vera tenía competencia, los testimonios suelen mencionar algunos en concreto. El citado cadí de Vera, Abrahen Yaçid, según su propio hijo, se desplazaba a varios lugares de su jurisdicción para conozer de qualesquier pleytos çiviles que se ofreçian entre veçinos de los dichos lugares, para fazer cartas de docte o partiçiones de bienes y también para conozer de los dichos pleytos çiviles y façer las dichas escripturas y para cassar y descassar. Otros testigos ${ }^{13}$ declaran, como respuesta a las preguntas formuladas en 1550 y 1559 , que el cadí de Vera hacía escrituras de dote, de particiones, de ventas y de casamientos y cualquier tipo de documentos y autos.

La confusión, antes apuntada, acerca de la división de competencias entre el cadí y el alcaide procede de las declaraciones de algunos testigos, que adjudican al primero los asuntos civiles y al segundo los criminales. Aunque la pregunta formulada en 1550 se refiere a la competencia del cadí de Vera sobre Huércal y Overa en materia penal, sorprendentemente Diego El Chilichi (PV, fol. 201v, año 1550) y Gonzalo Yaçid dejan bien clara la separación de las actuaciones judiciales, pues aseguran que el cometido del alcaide era apresar delincuentes y llevarlos a Vera donde eran sentençiados y castigados, mientras que al cadí correspondían los asuntos civiles, si bien es cierto que se refieren a ambos cargos - cadíes y alcaides- como responsables de la justicia, distintos pero complementarios, y en algunos casos como veremos más adelante, desempeñados por una misma persona.

Otros cometidos de los cadíes aparecen en las páginas del pleito. Con frecuencia se producían hechos y acontecimientos determinados por el principal factor condicionante de la zona: la frontera. Para dirimir, arbitrar y, en definitiva, resolver situaciones conflictivas, los habitantes de Vera recurrían al cadí. En ocasiones se trataba de personas que se habían pasado a una u otra parte de la frontera y habían cambiado de $\mathrm{fe}^{14}$; otras veces, de robos, cabalgadas en tierra

\footnotetext{
13 Algunos de los testigos que mencionan estas actuaciones civiles son: Luis Quexuel (PV, fol. 218v, año 1550), Garçia El Hadid (PV, fol. 219r, año 1550), Françisco Fajardo (PV, fol. 260r, año 1559) y Anton de Miras (PV, fol. 260v, año 1559).

14 Vid. en García Antón, J., «La tolerancia religiosa en la frontera de Murcia y Granada en los últimos tiempos del reino nazari», Murgetana, 57 (1980), 125-126, y Arcas Campoy, M., «La práctica jurídica», el caso de una cristiana de Lorca, que tras ser llevada a Vera, se convirtió al Islam y
} 
de cristianos y entrega de rastros de cautivos en tiempos de paz ${ }^{15}$ (Françisco de Medrano, PV, fol. 295r, año 1559; Juan Aldulayaque, PV, fol. 296r, año 1559).

Otras competencias son marcadamente políticas, como las referidas por los testigos Luis Alcamoyni (PV, fol. 139r, año 1534), Diego Elague (PV, fol. 209v, año 1550) y Jorge Maris (PV, fol. 238v, año 1559). Los dos primeros mencionan que el cadí de Vera, Hamete Elcadi, mandaba bastimentos para la gente de guerra en Guercal y Overa, y el último que vio cobrar al titular de esta ciudad los quintos y derechos de cavalgaduras ${ }^{16}$. En estos casos se demuestra que, condicionado por diversas circunstancias, como había sucedido en tiempos pasados, el cadí podía desempeñar una función de gobernante, de representante de la autoridad $(s u l t a \bar{a})^{17}$. Esta afirmación la avalan las declaraciones del citado Luis Alcamoyni y Garçia Tuxeyean ${ }^{18}$ quienes explican que el cadí de Vera quiere decir como gobernador, en palabras del primero, y el xeque governador, según el otro.

e) Jueces delegados, secretarios y alfaquíes

La figura del juez delegado $(n \bar{a} ' i b)^{19}$ también aparece en la fuente documental de este trabajo. El testimonio de Alonsso El Haquen (PV, fol. 220r, año 1550) es especialmente interesante, ya que indica incluso el nombre y el cargo de la persona delegada. Según su declaración, cuando los habitantes de Huércal y Overa tenían que resolver asuntos civiles (cartas de dote, particiones, etc.) ynbiavan a llamar a un escrivano que estava en la dicha çiudad de Vera que se

se casó con un musulmán. A instancias de la madre, el cadí la lleva a la línea fronteriza entre Lorca y Vera para que decida libremente. La mujer eligió quedarse en Vera.

15 De los conflictos fronterizos también podían encargase personas delegadas del cadí. Estos delegados son, sin duda, los llamados jueces de la frontera, de los que trata Seco de Lucena, L., «Los jueces de la frontera y los fieles del rastro», Miscelánea de Estudios Árabes y Hebraicos, VII (1958), 137-140.

${ }^{16}$ Se refiere al jums, el quinto del botín obtenido en una algazúa ( $g a z w$ ), equivalente al término cabalgada que aparece en el pleito. Vid. sobre el jums, Ibn Ŷuzayy, Qawānin al-ahkām, edición de 'A. 'A. Sayyid al-Ahl, Beirut, 1979, 168-170, y Arcas Campoy, M., «Teoría jurídica de la guerra santa: El Kitāb qidwat al-gāzī de Ibn Abī Zamanīn», Al-Andalus-Magreb, 1 (1993), 62-63.

17 Sobre el desempeño de tareas de gobierno por parte de los cadíes, véase el documentado trabajo de Fierro, M., «The qāộ as ruler», Actas del Simposio Internacional sobre Saber religioso y poder político en el Islam (Granada 1991), Madrid, 1994, 71-116.

18 Archivo de la Real Chancillería de Granada, 503-475-1. Dato proporcionado por J. F. Jiménez Alcázar. Asimismo, otro testigo, Françisco de Arrián Boamir, refiere que el cadí de Vera había nombrado un teniente de alcaide al que le encomendó llevar trigo de Mojácar a Huércal.

19 Calero Secall, M. ${ }^{\text {a }}$ I., «El juez delegado ( $n \bar{a}$ 'ib) del cadí en el reino nazarí de Granada», Andalucía Islámica, IV-V (1983-1986), 161-201, ofrece un elaborado estudio sobre esta función. 
llamava El Bejari el qual yba a hazer las dichas escripturas con poder del cadi que estava en la dicha çiudad de Vera.

Se trata, pues, de un secretario (kâtib) actuando como juez delegado $\left(n \bar{a}{ }^{\prime} i b\right)$ del cadí de Vera.

Por la parte de Lorca las noticias difieren por completo. Tanto las preguntas formuladas en 1550 y 1558 , como las respuestas de los testigos ${ }^{20}$ ponen de manifiesto la existencia de ciertos cadíes con competencias muy limitadas que iban por los pueblos y eran nombrados directamente por el soberano y cadí supremo de Granada. Sobre estos cadíes «itinerantes» informan varios testigos, entre ellos Garçia El Forruchel (PV, fol. 234r, año 1558), quien dice que heran hombres savios en su ley e hante los d(ic)hos cadis los becinos del d(ic)ho rreino de Granada hacían cartas de almahar ${ }^{21}$, que son las cartas de docte de los que se casavan, y los d(ic)hos cadis hacian partiçiones de las haciendas que dexavan los moros que se morían y, que los d(ic)hos cadis, este t(estig)o dixo que save y vio que yban por las çiudades a usar los d(ic)hos sus ofiçios.

Respecto a los alfaquíes (faqìh, pl. fuqahä'), la información se canaliza en dos sentidos. Algunos testigos de ambas partes atribuyen al cadí la condición de alfaquí. Es el caso de Gonzalo Yaçid, numerosas veces mencionado, cuando dice que su padre, Abrahen Yaçid, era cadí de Vera y alfaquí. Y, tal vez, se refiere al mismo cadí Pedro de Mercado (PV, fol. 335r, año 1559) cuando afirma que los habitantes de Huércal y Overa iban a Vera donde hacía las escrituras el alfaqui que llaman clerigo ${ }^{22}$ el qual alfaqui ponia la justiçia de Vera. La condición de alfaquí también aparece unida al cargo de cadí en la parte de Lorca, pues en una parte de una pregunta formulada en 1558 se pide a los testigos que digan si saben que los cadis heran alfaquis y hombres sabios en su lei y ellos declaravan las dudas de su ley.

El segundo tipo de información sobre alfaquíes se refiere a personas ajenas al cadiazgo. Los testigos mencionan a tres alfaquíes: El Guniça, alfaquí de Vera (Alonsso El Taverna, PV, fol. 206v, año 1550), un alfaquí de Arboleas, padre del testigo Françisco Navarro Elorayguaz (PV, fol. 219v, año 1550) y, por último, Gabriel Xazien, alfaquí de Huércal y Overa ${ }^{23}$.

20 Están recogidas en Arcas Campoy, M., «Noticias sobre el cadiazgo», 205-207.

${ }^{21}$ El término almahar es la transcripción romance de la voz dialectal andalusí $/ a l-m a h(a) r /$, la dote (Corriente, F., A Dictionary of Andalusi Arabic, 514 [mhr] /mah(a)rl, máhar, «dower»). En Pedro de Alcalá figura máhar, pl. muhúr, «casamiento la dote que se da» (Corriente, F., El léxico árabe andalusí según P. de Alcalá, Madrid 1988, 196; y Pezzi, E., El vocabulario de Pedro de Alcalá, Almería 1989, 109, 703).

${ }^{22}$ Clérigo es el término castellano correspondiente al arabismo cadí. Es una analogía de la correspondencia de padre sancto con cadí mayor.

23 Jiménez Alcázar, J. F., Huércal y Overa, 42: A.R.Ch. Granada. 503-475-1. Cuadernillo 2. 


\section{AlCAIDES}

Me ocupo aquí de las vinculaciones de los alcaides con la justicia, es decir, de sus actuaciones judiciales, pero antes hay que aclarar que en la fuente documental aparece siempre el término alcaide ${ }^{24}$, procedente del árabe $q \bar{a}^{\prime} i d{ }^{25}$, con un contenido semántico muy aproximado al de su étimo: gobernador, jefe militar.

Como en el caso de los cadíes, las referencias aportadas por los testigos quedan distribuidas en varios apartados: a) el alcaide de Vera; b) la jurisdicción territorial; c) el nombramiento de los alcaides; d) las competencias judiciales de los alcaides.

\section{a) El alcaide de Vera}

Varios testigos de ambas partes del pleito confirman la existencia de una alcaidía en Vera, cuyos titulares, los alcaides, ejercieron en algunas ocasiones funciones judiciales. También se refieren a ellos empleando el término justicias cuando los citan junto a los cadíes, o para expresar que tenían esta atribución.

Son mencionados los nombres de los siguientes alcaides con funciones judiciales:

- Hichi El Nayar, alcaide de Vera, coetáneo del citado cadí El Alçir (Diego El Chilichi, PV, fol. 164r, 201v, año 1550). Por los datos del testigo se le puede situar cronológicamente a partir de 1478.

- El Xeaynen o El Xaaynin, alcaide de Vera, al parecer de la misma época del cadí Abrahen Yaçid (Gonzalo Yaçiz, PV, fol. 203v, año 1550; Diego de Elague, PV, fol. 209v, año 1550).

- Mahomad Alcadi, según Pedro Nafar (PV, fol. 17r, año 1511) cuyo testimonio se remonta a 60 años atrás (a partir de 1451), este personaje era justiçia $y$ conçejo de Vera, lo que puede ser interpretado como alcaide y cadí. Sin duda, se trata de Alcadi El Biejo, antes mencionado en la relación de cadíes.

- Hamete El Cadi, antes citado como cadí y probablemente hijo del anterior, es uno de los personajes más nombrados por los testigos. A él se refieren como alcaide, cadí, caudillo, alguacil, gobernador y hombre principal de la ciudad de Vera.

${ }^{24}$ Corominas, J., Diccionario Crítico Etimológico Castellano e Hispano I, Madrid 1980: qā'id es el étimo de caíd, «juez o gobernador árabe», y de alcaide, "capitán», "gobernador de una ciudad».

${ }^{25}$ Según Encyclopédie de l'Islam, Nouvelle Édition, IV (1978), 476-477 (G. S. Colin), es un término poco preciso, referido a un jefe militar con funciones fiscales y judiciales. Pedro de Alcalá recoge la voz dialectal cáid con los significados de «alcaide», «teniente de fortaleza» y "caudillo assi», entre otros (Corriente, F., El léxico, 173; y Pezzi, E., El vocabulario, 41, 679). 


\section{b) La jurisdicción territorial}

La información contradictoria aportada por los testigos de las partes litigantes, como en el caso de los cadíes, viene determinada por la oposición de los intereses defendidos. Los de Vera afirman que varias poblaciones -entre ellas, Huércal y Overa - carecían de alcaide, por lo que se hallaban bajo la jurisdicción del titular de aquella ciudad. Algunos testigos se pronuncian al respecto empleando el término alcaide (Diego El Chilichi, PV, fol. 201v, año 1550; Gonçalo Yaçid, PV, fol. 303r, año 1550; Françisco Fajardo, PV, fol. 249r, 260r año 1559) y otros refiriéndose a ellos como justiçias (Françisco Lopez de Cardenas, PV, fol. 310r, año 1559; Alonso El Fahar, fol. 312r, año 1559; Françisco Beyiçora, PV, fol. 313r, año 1559).

Por el contrario, los testigos de Lorca sostienen que cada alcaide hacía justicia en su lugar. Así, Luis El Begeri (PL, fol. 8v, año 1511), Alfonso Al Folix (Pl, fol. 10r, año 1511), Alfonso Al Çuculi (Pl, fol. 11r, año 1511) y Diego Mendez Tarte (PL, fol. 140v, año 1550) mencionan la existencia de alcaides en Vera, Cuevas y Huércal, sin relación de dependencia alguna.

En 1558, en respuesta a una pregunta sobre la jurisdicción de los alcaides y alguaciles, los testigos Garçia El Forruchel (PL, fol. 224v, año 1558) y Gonçalo Hernandez Axir (PL, fol. 225r, año 1558) indican que las ciudades de Granada, Baza, Guadix, Purchena, Vera y Almería, independientes unas de otras, contaban con su propio alcaide y añaden que los lugares pequeños eran regidos por un alguacil, término que aquí tiene el significado de gobernador ${ }^{26}$, insistiendo en que cada pueblo tenía su término por sí y sobre sí.

En el caso de Huércal y Overa, la tesis de Lorca es avalada por la acogida en ambas villas de homicianos ${ }^{27}$ y perseguidos por la justicia de diversos lugares. Estos refugiados, amparados por un escrito real, quedaban bajo la absoluta autoridad del alcaide hasta cumplir los años establecidos defendiendo la frontera.

\footnotetext{
${ }^{26}$ Del árabe wazir, significa visir, ministro. Sin embargo Arié, R., Historia de España musulmana III (dirigida por M. Tuñón de Lara), Barcelona, 1982, 88-89, advierte la evolución semántica del término en el siglo xv, pues hay visires en poblaciones pequeñas como Jubiles, Capileira y Fiñana, lo que, según sus palabras, «sólo puede tratarse de gobernadores locales». Los dos testigos del pleito confirman lo apuntado por R. Arié.

27 Vid. sobre esta cuestión el análisis y conclusiones de varios testimonios sobre los homicianos en Arcas Campoy, M., «Ortodoxia y pragmatismo en el figh. Los homicianos de la frontera oriental nazarí» (nota núm. 2).
} 
c) El nombramiento de los alcaides

Todos los testigos están de acuerdo en que los alcaides eran nombrados por el monarca, pero los de Vera restringen este hecho sólo a los titulares de las ciudades importantes, entre las que se encuentra dicha ciudad. Son mencionados varios nombres de alcaides de Huércal y Overa (varios testigos, PV, fol. 106r110v, año 1528; Diego El Ague, PV, fol. 120v, año 1550), pero siempre haciendo constar que habían sido nombrados por Vera, en varios casos por su cadí y alcaide, Hamete Al Cadi.

Como cabe esperar, la parte de Lorca sostiene que todos los alcaides, cualquiera que fuese su sede, eran nombrados directamente por el rey granadino. Luis El Begeri (PL, fol. 8v, año 1511) afirma que su padre, nombrado por el monarca, fue alcaide de Cuevas durante diez años y los citados, Garçia El Forruchel (PL, fol. 224v, año 1558) y Gonçalo Hernandez Axir (PL, fol. 225r, año 1558) confirman el nombramiento real de los alcaides de todas las poblaciones. Sobre esta afirmación se insiste en una pregunta formulada en 1558 (PL, fol. 234v) en la que, entre otras cosas, se pide a los testigos que declaren si saben que ninguna çiudad aunque fuese Granada podia poner cadi ni alcaide ni alguaçil ni caudillo sino solo el rrei moro.

No obstante la contradicción al respecto manifestada por ambas partes, existe documentación que avala la tesis de Lorca. Se trata de unas cartas rea$\operatorname{les}^{28}$ en las que el monarca granadino nombra un alguacil y dos alcaides de Huércal.

d) Las competencias judiciales de los alcaides

Entre las atribuciones del representante de la autoridad (sulțān) se encuentran determinadas actuaciones judiciales, como la detención de delicuentes, el mantenimiento del orden público y la sentencia y ejecución de sanciones a su arbitrio $\left(t a{ }^{\prime} z i r\right)$ o de penas complementarias y subsidiarias $\left(t a^{\prime} d i b\right)$ de las llamadas taxativas $(h u d \bar{u} d)$, dictadas por el cadí ${ }^{29}$.

\footnotetext{
${ }^{28}$ El texto romanceado de estas cartas se conserva en el Archivo Municipal de Lorca y han sido estudiadas por Espinar, M., y Grima, J., «Estudio de algunas cartas de los reyes nazaríes dirigidas a los habitantes de Huércal (1409-1488)», Revista del Centro de Estudios Históricos de Granada y su Reino, 2 (1993), 39-57; Fontenla Ballesta, S., «Nueve cédulas reales de los últimos emires nazaríes», Boletín de la Asociación Española de Orientalistas, XXVIII (1992), 195-212, y XXIX (1993), 17-29. Los nombramientos aparecen en las cartas núms. 2, 5 y 7.

29 Arévalo, R., Derecho Penal Islámico. Escuela Malekita, Tánger, 1939, 69.
} 
El $q \bar{a}$ ' $i d$, es decir, el alcaide de la zona fronteriza que nos ocupa, como representante directo del monarca (sultāan), ejercía funciones de índole judicial. Así lo aseguran varios testigos del pleito en sus declaraciones, al margen del desacuerdo acerca de la jurisdicción territorial antes comentada.

Las actuaciones judiciales atribuidas a los alcaides de Vera y de otras poblaciones son principalmente en materia penal. El alcaide El Nayar de Vera (Diego El Chilichi, fol. 201v, año 1550) tenía la jurisdiçion y gobernaçion de Huércal y Overa, enbiando a prender los delinquentes que hacían delitos en los dichos lugares y llevandolos pressos a Vera donde heran sentençiados y castigados. En términos muy parecidos se expresa Gonçalo Yaçid (PV, fol. 203r, año 1550), refiriéndose al alcaide El Xeaynen.

Por la parte de Lorca hay varios testimonios referentes a la competencia penal de los alcaides. Luis El Begeri (PL, fol. 8v, año 1511), manifiesta que los alcaides tenian cargo de la just(ici) a criminal y ellos conozian y determinavan los pleytos que sobre los casos criminales acontezian. Otros testigos (Alfonso Al Folix, PL, fol. 10r, año 1511; Alfonso Al-Çuculi, PL, fol. 11r, año 1511; Diego Mendez Tarte, PL, fol. 140v-141r, 149v, año 1550), defienden lo mismo, pero destaco aquí las palabras concluyentes de Alonso Peña (PL, fol. 68v, año 1512) respecto a los alcaides: en la d(ic)ha Huercal como en las otras partes del reino de Granada donde abia alcaide en tiempo de moros los $d(i c)$ hos alcaides heran las justiçias y ahorcavan y degollavan y los que haçian la justiçia.

En otras ocasiones los testigos no son tan concretos, sino que aluden al hecho de que los alcaides o estos junto con los cadíes eran los encargados de poner justicia. Sólo un testimonio, el de Alfonso Al Folix (PL, fol. 10r, año 1511), atribuye al alcaide competencias en materia civil, pues dice, refiriéndose al titular de Vera, que ante él los vezinos e moradores de la d(ic)ha villa de Las Cuevas yban a pleytos asi sovre casamientos como sobre herenzias o deudas de dineros o de otras cosas en que el dicho alcayde conozia de los dichos pleytos entre ellos y los determinava y sentenziava. Esta declaración suscita dos interpretaciones: a) alude a una misma persona ejerciendo el cadiazgo y la alcaidía; b) se refiere al alcaide, como representante del sultān, entre cuyas funciones judiciales se encuentran algunas en materia civil ${ }^{30}$.

\footnotetext{
${ }^{30}$ Las competencias del sultān en determinados casos civiles han sido estudiadas por Yanagihashi, H., «The judicial functions of the sultān in civil cases according to the Mālikis up to the sixth/twelfth century», Islamic Law and Society, vol. 3, 1 (1996), 41-74.
} 


\section{CONCLUSIONES}

Varias son las reflexiones, en algunos casos concluyentes, sobre lo anteriormente expuesto.

Teniendo siempre en cuenta que el marco geográfico al que se refiere este estudio es un espacio fronterizo del reino de Granada, en los últimos años de su existencia, las declaraciones de los testigos del pleito entre Lorca y Vera permiten deducir, entre otras cosas, las siguientes:

- Vera, la ciudad más extrema de la frontera oriental, era una sede judicial con un cadí a su cargo, nombrado por el monarca granadino y el cadí supremo.

- Parece probado que el cadí de Vera tenía bajo su jurisdicción todas las poblaciones menores de su entorno ${ }^{31}$ y que sus habitantes se desplazaban a su sede o lo hacía el cadí a los lugares donde era requerido.

También hay constancia del ejercicio de la delegación (niyāba) del cadiazgo. Tal es el caso de un escribano, delegado (nă'ib) del cadí de Vera, con actuaciones judiciales en Huércal. Sin embargo, queda por resolver el problema planteado por los testigos de Lorca cuando se refieren a ciertos cadíes itinerantes nombrados por el monarca y el cadí supremo para resolver casos civiles de poca importancia ${ }^{32}$.

- La mayoría de los testigos adjudican al cadí las competencias propias de su cargo, en materia civil y penal, si bien es patente que, en determinados momentos, el cadí asumió otras funciones de carácter administrativo y de gobierno (cobro de impuestos, rescate de cautivos, etc.). Este hecho, determinado por su espacio y su tiempo - la frontera oriental de Granada en la segunda mitad del siglo xv-, confirma el poder político que los cadíes tuvieron en diferentes ocasiones a lo largo de la historia de al-Andalus.

- Los alcaides, representantes de la autoridad (sultānn), tenían competencias judiciales en materia penal: detención, apresamiento y castigo de delincuentes. Por último, hay que destacar que el cargo de alcaide y cadí, en algunas ocasiones, recayó en una misma persona, asumiendo las competencias correspondientes. Esto, sin duda, tenía lugar cuando se producía un vacío de poder en uno u otro cargo. Así, el cadí asumía las funciones de alcaide en ausencia de éste y viceversa.

\footnotetext{
${ }^{31}$ Jiménez Alcázar, J. F., Huércal y Overa, 24-25 afirma que Vera, como cabeza de distrito o $t_{a}^{c} a$, representaba un espacio «incluso de núcleos bastante lejanos», de unos $25 \mathrm{~km}$. Esa misma jurisdicción territorial podría corresponder al cadí.

${ }^{32}$ Lévi-Provençal, E., Historia de España (dirigida por R. Menéndez Pidal), 20 ed., tomo V, 74 , alude a presencia de «juececillos» en pueblos para litigios de poca monta.
} 


\title{
RESUMEN
}

Este trabajo se centra, dentro del marco de la práctica jurídica, en la actividad judicial en la frontera oriental granadina en los últimos años del reino nazarí. La fuente documental es el pleito que Lorca (Murcia) y Vera (Almería) sostuvieron por la delimitación de sus términos a lo largo del siglo XVI. La información viva y real aportada por los testigos, en su mayoría cristianos nuevos y de avanzada edad, viene a arrojar luz sobre la delimitación de competencias, actuaciones y jurisdicciones no sólo del cadí, sino también del alcaide, otro importante representante de la justicia, en un espacio concreto de al-Andalus y en un tiempo concreto de su historia.

\begin{abstract}
This article deals with the judicial activity which took place on the eastern frontier of Granada at the end of the Nasrid kingdom. The source from which the data are taken is a dispute between the towns of Lorca (Murcia) and Vera (Almería) concerning the delimitation of their borders. This dispute took place during the sixteenth century. The information given by the witnesses is quite vivid and real. The witnesses were mostly elderly new Christians. Their testimonies provide a wide range of data on the activities of the $q \bar{a} \bar{c} \bar{i}$, as well as on those of the $q \bar{a}$ 'id related to legal matters and they allow us to reconstruct the sphere of justice in a specific territory and specific time in the history of al-Andalus.
\end{abstract}

